\title{
choer
}

\section{Avaliando programas de microcrédito e economia solidária do Banco do Nordeste}

\author{
Raul da Fonseca Silva Thé \\ Mestre em Sociologia pela Universidade Estadual do Ceará UECE \\ Bacharel em Ciências Sociais pela Universidade Federal do Ceará \\ UFC \\ raulsilvathe@gmail.com \\ https://orcid.org/0000-0002-0317-7077
}

\section{Alcides Fernando Gussi}

Doutor em Educação pela Universidade Estadual de Campinas

Unicamp

Professor na Universidade Federal do Ceará UFC

agussi@uol.com.br

https://orcid.org/0000-0002-5510-5286

\section{Resumo}

\begin{abstract}
Duas experiências distintas no campo das microfinanças promovidas pelo Banco do Nordeste do Brasil S.A. (BNB) são avaliadas neste artigo: a) Programa Crediamigo, de microcrédito urbano produtivo orientado; e b) Programa de Apoio a Projetos Produtivos Solidários (PAPPS), de acordo com os princípios da economia solidária. Para tanto, o enfoque etnográfico é apresentado como importante metodologia no desenvolvimento de processos avaliativos. Almeja-se o alcance de indivíduos que pertencem ao mesmo grupo social, porém, eles constituem públicos diferentes e recebem atenção, impactos e investimentos díspares em relação a suas vidas e trajetórias, a depender dos programas em que se inserem. Os resultados mapeiam como essas duas políticas dialogam, ao mesmo tempo que diferem e se distanciam em termos de foco e peso atribuídos às dimensões econômicas, sociais e políticas do Nordeste brasileiro. À guisa de conclusão, evidencia-se: a) a lógica seguida pelos programas; b) os impactos proporcionados na vida dos indivíduos; e c) as qualidades, os limites e as possibilidades desses programas.
\end{abstract}

Palavras-chave políticas públicas; microcrédito; economia solidária; banco de desenvolvimento.

\footnotetext{
Conhecer: debate entre o público e o privado 2020, Vol. 10, ำ 24

ISSN 2238-0426

DOI https://doi.org/10.32335/2238-0426.2020.10.24.2071

Licença Creative Commons Atribuição (CC BY 4.0)

Data de submissão 21 out 19

Data de publicação 20 jan 20
} 


\title{
Evaluating the Banco do Nordeste's microcredit and solidarity economy programs
}

\begin{abstract}
Two distinct experiences in the field of microfinance promoted by the Banco do Nordeste do Brasil S.A. (BNB) are assessed in this article: a) Programa Crediamigo, directed productive urban microcredit; and b) Programa de Apoio a Projetos Produtivos Solidários (PAPPS), according to the principles of solidarity economy. Therefore, the ethnographic approach is presented as a valuable methodology to devise assessment processes. The goal is to reach individuals belonging to the same social group, but they constitute different target customer groups and receive very different levels of attention, impact, and investment in relation to their lives and trajectories, depending on the programs which they are inserted in. The results map how these two policies dialogue, while differing and detaching from each other in terms of focus and weight assigned to the economic, social, and political dimensions of Brazil's Northeast Region. By way of conclusion, we evidenced: a) the rationale behind the programs; b) the impacts on the individuals' lives; and c) the qualities, limits, and possibilities of these programs.
\end{abstract}

Key words public policy; microcredit; solidarity economy; development bank.

\section{Evaluación de programas de microcrédito y economía solidaria del Banco do Nordeste}

\section{Resumen}

Este artículo evalúa dos experiencias distintas en el campo de las microfinanzas promovidas por el Banco do Nordeste do Brasil S.A. (BNB): a) Programa Crediamigo, microcrédito urbano productivo dirigido; y b) Programa de Apoio a Projetos Produtivos Solidários (PAPPS), de acuerdo con los principios de la economía solidaria. Por lo tanto, el enfoque etnográfico se presenta como una metodología importante para desarrollar procesos de evaluación. El objetivo es llegar a las personas que pertenecen al mismo grupo social, pero ellas constituyen públicos diferentes y reciben niveles muy diferentes de atención, impacto e inversión en relación con sus vidas y trayectorias, dependiendo de los programas en los que se insertan. Los resultados mapean cómo estas dos políticas dialogan, mientras difieren y se distancian en términos de enfoque y peso atribuidos a las dimensiones económicas, sociales y políticas de la Región Nordeste de Brasil. A modo de conclusión, evidenciamos: a) la lógica detrás de los programas; b) los impactos en la vida de las personas; y c) las cualidades, los límites y las posibilidades de estos programas.

Palabras clave políticas públicas; microcrédito; economía solidaria; banco de desarrollo. 


\title{
Évaluation des programmes de microcrédit et d'économie solidaire de Banco do Nordeste
}

\begin{abstract}
Résumé
Deux expériences distinctes dans le domaine de la microfinance promues par le Banco do Nordeste do Brasil S.A. (BNB) sont évaluées dans cet article: a) Programa Crediamigo, microcrédit urbain productif dirigé; et b) Programa de Apoio a Projetos Produtivos Solidários (PAPPS), conformément aux principes de l'économie solidaire. Par conséquent, l'approche ethnographique est présentée comme une méthodologie importante dans l'élaboration de processus d'évaluation. L'objectif est d'atteindre des individus appartenant au même groupe social, mais ils constituent des publics distincts et reçoivent des niveaux d'attention, d'impact et d'investissement très différents en fonction des programmes dans lesquels elles s'insèrent. Les résultats montrent comment ces deux politiques dialoguent, tout en se différenciant et en se distanciant en termes de concentration et de poids attribués aux dimensions économiques, sociales et politiques du Nord-Est du Brésil. En guise de conclusion, nous avons mis en évidence: a) la logique suivie par les programmes; b) les impacts sur la vie des individus; et c) les qualités, limites et possibilités de ces programmes.
\end{abstract}

Mots-clés politiques publiques; microcrédit; économie solidaire; banque de développement.

\section{Introdução}

Este artigo apresenta uma avaliação de programas distintos (de microcrédito e de economia solidária), ambos executados pelo Banco do Nordeste do Brasil S.A. (BNB). Além disso, aponta as contribuições que a abordagem etnográfica pode proporcionar para desenvolver a avaliação de políticas públicas. Esta é operacionalizada pelo acompanhamento da trajetória de duas iniciativas: a) Programa Crediamigo, de microcrédito urbano produtivo orientado; e b) Programa de Apoio a Projetos Produtivos Solidários (PAPPS), de acordo com os princípios da economia solidária.

Para tanto, realizou-se uma pesquisa empírica, de caráter qualitativo, centrada na compreensão desses programas (de microcrédito e economia solidária) e na inserção deles no Nordeste brasileiro, visando a pontuar seus limites e suas possibilidades.

O texto se organiza em 4 seções: a) descrição metodológica do processo avaliativo; b) apresentação dos resultados de pesquisa (tratamento avaliativo dos programas); c) discussão do processo de avaliação dos programas; e d) considerações finais.

\section{Metodologia}

A metodologia da avaliação se centrou na abordagem etnográfica, que focaliza as interpretações dos distintos indivíduos envolvidos nas políticas públicas. Esse procedimento, de natureza qualitativa, possibilitou a apreensão das representações, das visões de mundo e das perspectivas dos atores nos programas avaliados. 
Segundo a perspectiva etnográfica posta para a avaliação de programas e políticas públicas, de acordo com Gussi (2014), deve-se conhecer e reconhecer os diferentes atores institucionais e destinatários do programa ou da política em questão, ao passo que se executa um processo de imersão no campo empírico da política. Posteriormente, o compromisso com esse exercício consiste em definir estratégias metodológicas participativas, buscando os vários entendimentos, por exemplo, acerca da política ou do programa, seus objetivos, suas ações e seus resultados, compreendidos por diferentes indivíduos (agentes institucionais, beneficiários), ao que se pode associar aspectos a verificar in loco, relacionados com a política ou o programa. A proposição é construir metodologicamente - no campo - a experiência de uma política/um programa, por exemplo - sua trajetória - no contexto de uma instituição ou uma comunidade local específica' .

Para tanto, no caso da avaliação dos programas de microcrédito, buscou-se compreender os sentidos e significados elaborados pelos atores - funcionários do Banco do Nordeste e os beneficiários - durante as ações de operacionalização dos distintos programas focalizados aqui. De outra maneira, apontaram-se as interpretações dispostas e publicizadas ou as diferentes ideias acionadas publicamente, no sentido de realizar, nos termos de Geertz (1989), uma "descrição densa", uma etnografia que representasse o campo apresentado à pesquisa avaliativa.

Dentro dessa perspectiva, acompanharam-se as trajetórias institucionais dos programas Crediamigo e PAPPS, partindo da noção de trajetória de Bourdieu (1986). Tem-se como centro a ideia de que políticas, programas e projetos não têm sentido e iniciativa únicos e que estão circunscritos a ressignificações dos atores envolvidos, segundo os vários posicionamentos nos contextos em que se insere o programa (Gussi, 2008).

Para tanto, a construção da pesquisa etnográfica adotada para a avaliação dos programas de microcrédito envolveu as seguintes etapas de pesquisa:

- Pesquisa bibliográfica sobre microcrédito, microfinanças e desenvolvimento, dentre outras temáticas, com consulta nas bases de dados disponíveis na internet;

- Coleta de material institucional sobre os programas (desenho dos programas, objetivos, características, dados quantitativos de investimentos e de desempenho e seus impactos nas comunidades locais);

- Mapeamento estatístico dos programas no bairro pesquisado no Município de Fortaleza;

- Entrevistas qualitativas com os atores institucionais que conceberam e implementaram os programas em Fortaleza, abordando seus objetivos, conceitos

1 Trata-se de uma proposição alinhada à perspectiva de Lejano (2011) para a análise de políticas, baseada na problematização da noção de experiência da política. Para o autor, a política deve ser compreendia em seu cotidiano, na prática dos atores sociais nela envolvidos, em seus contextos específicos. Ressalta-se que tal proposição inspira novas metodologias de avaliação, conforme Rodrigues (2008) e Gussi (2014), baseadas em referenciais qualitativos de recorte etnográfico. 
centrais, inspiração teórica e metodologia, bem como a avaliação dos programas;

- Aplicação de questionários a beneficiários dos programas, com o intuito de traçar dados acerca do perfil socioeconômico dos beneficiários, como sexo, idade, estado civil, localidade de origem, orientação religiosa, profissão, situação econômica e familiar e qualificação profissional, em uma perspectiva comparativa anterior e posterior ao empréstimo recebido;

- Observação participante nos loci das experiências gestadas pelos programas, com a verificação da vida familiar e do empreendimento de trabalho gerado pelo microcrédito;

- Trajetórias dos beneficiários, escolhidos a partir dos perfis dos questionários, e sua vinculação com os programas² .

A próxima seção apresenta o tratamento avaliativo dos programas Crediamigo e PAPPS do Banco do Nordeste.

\section{Resultados}

\section{Avaliação do Programa Crediamigo}

O Crediamigo é o programa de microcrédito (urbano) produtivo orientado do Banco do Nordeste. É fruto da ação pioneira de um banco público do Brasil, apoiado pelo Governo Federal e por parceiros internacionais.

Iniciou-se como projeto-piloto em 1997, passando efetivamente a operar em 1998 com a abertura de 45 unidades. Atualmente está presente em 1.481 municípios do Nordeste ou toda a área de atuação do banco (14 estados brasileiros), contando com mais de 2 milhões de clientes ativos (Banco do Nordeste do Brasil [BNB], 2018, 2019). O Crediamigo tem por finalidade fornecer pequenos empréstimos, de $\mathrm{R} \$ 100,00$ a $\mathrm{R} \$ 15.000,00$, de acordo com a necessidade e o porte do negócio. Tal crédito se realiza de forma não burocrática, para que nanoempreendedores financiem seus negócios em troca do chamado "aval solidário", uma garantia, oferecida pelo empréstimo, em nome de um grupo formado para tanto, de modo que não seja fornecido individualmente, mas a grupos de pessoas que se responsabilizam solidariamente por seu pagamento.

O seu público-alvo, sobretudo o de baixa renda, é constituído por autônomos, donos de pequenos negócios e trabalhadores informais que necessitam de crédito para gerar fonte de renda, no setor da indústria, do comércio ou de serviços. Notadamente, os empréstimos concedidos são destinados à formação de capital de giro, o "Giro Popular Solidário", à aquisição de máquinas e equipamentos e à realização de reformas.

2 Para aprofundamento sobre a técnica de história de vida e suas possibilidades na pesquisa social, ver Gussi (2004). 
A atuação do Crediamigo pode ser compreendida por meio da relevância atribuída à preferência do programa por clientes com menor possibilidade de inclusão no sistema bancário. Portanto, cerca de $50 \%$ do total de clientes ingressam no nível de subsistência (BNB, 2018, 2019) ou na condição de survivor (autoempregado, por falta de alternativa) ${ }^{3}$ (Santos, 2007) demonstrando que a atuação do programa se situa na faixa da base da pirâmide social, voltada especialmente ao gênero feminino (que absorve $67 \%$ das aplicações de crédito).

Com o objetivo de avaliar o Crediamigo, acompanhamos o programa em seu contexto institucional e buscamos os sentidos e significados atribuídos pelos atores institucionais e beneficiários que se vinculam às suas ações. Esse processo foi realizado em duas frentes, delineadas pelo método etnográfico: uma vinculada à pesquisa por meio do acompanhamento e da descrição de eventos institucionais do Banco do Nordeste, com referência explícita e/ou implícita ao Programa Crediamigo; outra, em uma vertente de observação das representações e dos significados identificados no discurso de 11 funcionários do Banco do Nordeste, de diferentes áreas, sobre o Crediamigo e visões particulares sobre desenvolvimento, em correlação com as ações da própria instituição. Apresentamos, sucintamente, os resultados dessas duas frentes de pesquisa.

Os eventos nos levaram a apresentar o Programa Crediamigo como estratégia central na proposta de desenvolvimento do banco no atual contexto político-institucional, atrelado, por um lado, a programas federais de erradicação da pobreza e, por outro, à estratégia de ampliação de mercado do próprio banco.

Nos discursos institucionais, observamos uma localização institucional dos distintos programas avaliados, que se associam aos persistentes programas sociais de transferência de renda do Governo Federal, como o Bolsa Família, em que ambos atendem à base da pirâmide social brasileira (em especial o Crediamigo). Além disso, podemos observar diferentes lugares de fala e distintas formas de interpretar as estratégias de cunho mercadológico e social, escolhidas pelo banco ao longo da história e no atual contexto. Nos discursos, concluímos que há um embate de visões dos funcionários quanto à posição institucional do Banco do Nordeste entre ser um banco de mercado ou um banco de desenvolvimento social.

Realizou-se, também, a construção do perfil socioeconômico do universo dos clientes pesquisados: revelou-se que $94 \%$ dos indivíduos eram do sexo feminino, o que destaca o recorte de gênero nas atividades de microcrédito. Em relação à idade dos participantes, $45 \%$ se encontravam na faixa etária entre 36 e 50 anos, enquanto $29 \%$ tinham entre 51 e 65 anos. Quanto ao estado civil, 67\% dos entrevistados eram casados ou viviam em

3 Para o self-employed (autoempregado), a que se referem Nitsch e Santos (2001), o microcrédito cumpriria uma tarefa social, como instrumento, de forma indireta, de combate à pobreza, ao mesmo tempo que fomenta o desenvolvimento econômico. 
união estável, representando um acréscimo de 4,5\% no tempo de ingresso no programa. A escolaridade dos entrevistados se caracteriza assim: 43,75\% têm Ensino Médio; 50\% têm Ensino Fundamental; e 6,25\% são analfabetos.

Desse perfil, depreende-se que o Crediamigo atinge, nessa faixa de renda, a trabalhadora informal, de meia-idade, casada, excluída do mercado de trabalho formal. Ao recorrer ao Crediamigo, essas mulheres almejam prover ou ampliar sua renda, ainda nos quadros das atividades informais, geralmente como comerciantes de cosméticos e alimentos, cabeleireiras, manicures e costureiras, algumas delas buscando mudar sua categoria de trabalho, sobretudo as que vivem do emprego doméstico.

A análise dos resultados da pesquisa avaliativa sobre o Crediamigo aponta 0 programa como impactante na renda dos clientes, ampliador do crédito nas classes mais baixas, bem como catalisador da ampliação e mudança do perfil laboral e de renda. Os clientes inferem a ideia de que o programa está inscrito no Banco do Nordeste. Ou seja: o Crediamigo se orienta, primeiramente, à dimensão econômica, com foco no aumento da renda e do consumo dos clientes, implicando um desenvolvimento vinculado à inclusão laboral, ao consumo individual e ao efeito indireto no próprio mercado.

Dentro desse espectro e apesar desse quadro, a condição de vida dos clientes permaneceu estável, alterando-se apenas a condição de consumo doméstico das famílias envolvidas, sem mudança significativa em outros aspectos da vida, como escolaridade, capacitação profissional, moradia, saúde e lazer. A apreensão dessas necessidades surge nos beneficiários no momento em que se afirma, por um lado, a cidadania a partir da inclusão pelo consumo, mas, por outro, aponta a necessidade de maior aprofundamento da política por meio de capacitação para o trabalho, qualidade de informação e conhecimento para as atividades e a melhoria das condições de vida em geral, para além do consumo.

As narrativas desses beneficiários elucidam a oportunidade que o programa de microcrédito oferece a seus clientes, de obterem um empréstimo com baixas taxas de juros, algo que outros bancos não Ihes possibilitam, facilitando que montem e/ou deem continuidade a um negócio próprio e podendo, assim, ter uma fonte de renda que se revela uma alternativa para aqueles que não estão inseridos no mercado formal de trabalho. Por outro lado, por meio de algumas críticas a determinados pontos do programa ou até do silêncio gerado após perguntas sobre os aspectos negativos dele, percebemos que os clientes consideram que o Crediamigo apresenta limitações e não satisfaz completamente suas necessidades sociais. 


\section{Avaliação do Programa de Apoio a Projetos Produtivos Solidá- rios}

O PAPPS teve início em 2005 no Banco do Nordeste. Mediante convênio com a Secretaria Nacional de Economia Solidária (SENAES), do Ministério do Trabalho e Emprego (MTE), o banco estabeleceu parcerias na execução de programa de apoio a organizações que operam com fundos rotativos solidários (FRS), segundo os nexos das microfinanças e da economia solidária.

O PAPPS, em seus próprios termos, define-se como uma estratégia diferenciada e autossustentável do Banco do Nordeste, para beneficiar diretamente as comunidades rurais e urbanas, contribuindo para sua emancipação social e econômica a partir da afirmação da solidariedade. Partindo disso, os FRS, ao fornecerem financiamento, consideram a possibilidade de que o dinheiro aplicado nas atividades possa produzir efeito e ser devolvido, a fim de beneficiar outros participantes.

Dentre os projetos apoiados em 2008, destaca-se a destinação de recursos para a formação do FRS da Rede Bodega, nos municípios de Aracati, Fortaleza, Sobral e Tianguá, no Ceará. Integrante da Rede Bodega, a Associação das Mulheres em Ação (AMA/Budeg'AMA) recebeu parte desses recursos para uso na criação do FRS, destinado à produção e comercialização das associadas, cujas repercussões foram objeto de nossa pesquisa avaliativa, tomado como estudo de caso do PAPPS no Banco do Nordeste.

Na pesquisa avaliativa, procuramos traçar o perfil socioeconômico das associadas da Budeg'AMA em termos de: a) escolaridade; b) moradia; c) vida profissional; d) renda recebida na associação; e) despesas; e f) condições de vida e de trabalho. Além de observar o uso dos recursos do PAPPS para a composição do FRS da própria AMA.

Assim, dentre as 10 mulheres entrevistadas, a maioria ou é casada (70\%) ou é viúva. As idades variam de 41 a 67 anos (com 50\% acima de 60 anos). Quanto à escolaridade, observa-se que 60\% fizeram Ensino Médio (completo ou incompleto), sendo que $60 \%$ frequentam cursos, seja do ensino formal ou informal. Uma delas faz curso superior.

Quanto à moradia, 70\% possuem casa própria, adquirida antes da AMA. Há equilíbrio no compartilhamento da moradia: $40 \%$ moram com marido e filho. Computando-se aquelas que moram com marido, filhos e netos, as que residem com marido, filhos e cunhados e as que habitam com marido, filhos e pais, esse índice sobe para $80 \%$.

No tocante à vida profissional, no período anterior à entrada na AMA, 40\% tiveram carteira assinada e $60 \%$ nunca tiveram. Ou seja, as trajetórias profissionais dessas mulheres se voltaram ao trabalho informal, seja por falta de oportunidade ou de opção.

Em relação ao trabalho atual na AMA, $60 \%$ o realizam na própria sede e as outras $40 \%$ trabalham em casa. Isso porque o trabalho na sede geralmente é realizado pelas mulheres que fazem parte da Budeg'AMA. As demais optaram por não comercializar seus produtos 
na loja para não ter de contribuir com as despesas da sede, já que estas comprometem os ganhos (que não são elevados). Quanto à participação em outras atividades remuneradas, além da realizada na AMA/Budeg'AMA, 80\% responderam não ter outra ocupação, demonstrando que a AMA é o principal local de produção.

Finalmente, quanto à renda com o trabalho na AMA/Budeg'AMA e à renda familiar: para $60 \%$ das mulheres, os ganhos auferidos na atividade da AMA variam entre $\mathrm{R} \$ 100 \mathrm{e}$ $\mathrm{R} \$ 200$ por mês, valores ainda diminutos. E na composição da renda familiar, além daquela gerada pelo trabalho na AMA/Budeg'AMA, 70\% delas complementam a manutenção da casa com o marido, ao passo que as demais contaram com pensão (no caso das viúvas).

Partindo desse perfil, buscamos aprofundar a dimensão qualitativa da avaliação ao conhecer: a) por um lado, a visão das associadas sobre os recursos do PAPPS e as modificações, acaso percebidas, a partir de sua aplicação na AMA, bem como a importância para manutenção do empreendimento; e b) por outro lado, a visão sobre o PAPPS dos gestores do Banco do Nordeste.

Pelos relatos das associadas da AMA/Budeg'AMA, percebe-se que foram significativas as transformações pelas quais passaram, a partir de sua entrada na entidade. A maior delas talvez tenha sido passar a trabalhar fora de casa, na maioria das vezes sem o apoio familiar. Assim, do ponto de vista pessoal, a emancipação foi um dos maiores ganhos. Do ponto de vista profissional, o fato de ter uma ocupação garantiu maior respeito perante a família, que antes negava seu apoio.

Nas manifestações sobre o tema economia solidária, percebe-se o desafio de trabalhar os conceitos de solidariedade, afetividade e autogestão, contrários ao sistema vigente. Mas isso acaba tornando-se uma prática menos difícil, já que contam com o apoio de órgãos institucionais, a exemplo do Banco do Nordeste, encontrando incentivos para continuar o projeto em que acreditam, obter uma renda, poder praticar um ofício, enfim, verificar que há possibilidades de uma vida melhor e mais digna. Dessa forma, analisamos as visões das associadas a partir das seguintes dimensões: a) social; b) econômica; c) política; e d) ambiental.

Nas narrativas das associadas, a dimensão social é caracterizada pelas relações concernentes ao FRS e à operacionalização da solidariedade, pontuando as mudanças em suas vidas, antes e depois da AMA, a partir do trabalho realizado e da renda extra. $\mathrm{Na}$ dimensão econômica se vê que os recursos do PAPPS na AMA/Budeg'AMA são considerados relevantes, especialmente na formação do fundo, mas expressam dúvidas e preocupações acerca da dependência criada em relação ao fundo, além de entenderem o retorno financeiro como menor do que suas necessidades como grupo, como indivíduos e como fundo. A dimensão política é apontada pelas associadas como um objetivo alcançado, já que reconhecem a ampliação da participação, o aprofundamento democrático nas decisões e um fortalecimento da autogestão, além de transparência e divisão equânime de ganhos. $\mathrm{E}$ 
a dimensão ambiental envolve o respeito, a consciência e a produção voltados a garantir o uso de materiais recicláveis no processo. Em síntese, percebe-se que os objetivos atingidos - segundo a narrativa das participantes - concentram-se muito mais nas dimensões social, política e ambiental do que propriamente na dimensão econômica.

Já a visão institucional - de agentes institucionais do Banco do Nordeste - acerca dos processos operacionais do PAPPS aponta fragilidade na gestão dos fundos - por parte dos contemplados e da instituição. Fundos que se mostram comprometidos pela falta de ampliação de recursos propõem, como visão de atuação, estimular os impactos nas dimensões social, política e ambiental.

Assim, para o pensamento institucional, a dimensão socia/ cumpre seu papel ao formar e fortalecer a prática coletiva e as relações solidárias, contribuindo para a fortificação dos empreendimentos ao tempo que tonifica a cooperação e o associativismo, além de ser fundamental para a mudança social. A dimensão econômica tem entre os funcionários uma avaliação controversa acerca do volume aportado de recursos, mas, mesmo não sendo unânimes sobre qual volume seria suficiente para esses contemplados, acreditam que o atual aporte impacta positivamente as vidas dos beneficiários. A dimensão política é vista pelos gestores como um dos grandes benefícios, já que aflora com os FRS uma maior discussão sobre a (auto)gestão, assumindo destaque a cooperação e a cidadania gestados nesse processo. E a dimensão ambiental é pontuada pelos funcionários como uma das obrigações para a obtenção do PAPPS e que as participantes vêm demonstrando cuidado com essa questão.

A partir desses pontos de vista, construiu-se um panorama avaliativo sobre o PAPPS de acordo com cada uma das dimensões. Dessa maneira, compreendemos que a dimensão social promoveu ampliação de laços e sociabilidade solidária e cooperativa, incentivando os projetos pessoais de autonomia das associadas a partir do trabalho coletivo e da produção e (auto)gestão participativa e contraposta ao mercado capitalista. Na dimensão econômica se encontra a maior limitação do programa, já que auxiliou parcialmente, com a criação do FRS, mas o aporte desse fundo somado à renda obtida pelo grupo passa longe de garantir a autonomia econômica almejada. A dimensão política se desenvolveu como contribuição para a construção de uma cultura autogestionária democrática, com formulação de uma consciência política e de cidadania. E a dimensão ambiental tem relevância menor, apesar de auxiliar na formulação de uma consciência e um compromisso ambiental. 


\section{Discussão}

\section{Observando os programas, revelando realidades}

A ideia desses programas (microcrédito e economia solidária) advém, nas palavras de Raczynski (1995, p. 14, tradução nossa), de uma "hipótese surgida em vários países que propõe a 'feminização' da pobreza no âmbito urbano”, o que torna compreensíveis os encaminhamentos citados para o gênero feminino. Da mesma forma, a autora identifica que a focalização é necessária nesse tipo de programa, que se dedica a gerar oportunidades em setores excluídos, para que haja superação dos quadros de pobreza e vulnerabilidade.

Fica evidente na construção das políticas de crédito do Banco do Nordeste que, apesar de haver um trabalho e uma preocupação de estimular o crescimento da renda na área, também há interesse de construir outros determinantes para a saída da pobreza ou, como entende Sen (2010), o crédito funcionaria como gerador de capacidades que impulsionariam a saída da pobreza. Entretanto, esse é um lado da construção de políticas para a base da pirâmide social da clientela do Banco do Nordeste que evidencia uma perversa lógica de manutenção de capital bancário, de adensamento de contas ativas e de transformação, em áreas de renda média baixa, da confiança e do afeto anteriores ao crédito em dados colaterais.

Esses programas se alinham, nas palavras de Rist (2002), à ideia de "empreendedorismo", segundo o entendimento de Schumpeter (1997), de que o indivíduo (empreendedor), nessa lógica, antes de ser empreendedor deve ser devedor. Portanto, são fundamentos opostos à visão defendida por Furtado $(1997,1998,2007)$ de autonomia e de autoafirmação regional e dos indivíduos. Assim, a posição de "(nano)empreendedor" não conota, na gestão do banco, autonomia ou autoafirmação, antes se apresenta como uma posição de devedor e, portanto, de dependência.

Há mais de 21 anos (cerca de 1/4 da história da entidade), o Crediamigo atua no Banco do Nordeste categoricamente como estratégia para o "desenvolvimento" e como resposta ao que, como reportou Dimenstein (1997), o ex-presidente Fernando Henrique Cardoso (FHC) denominou trabalhadores "inempregáveis"4. Essa é uma solução que passa por uma diretriz, um discurso e uma prática extremamente liberais e centralmente vinculados ao mercado e, nas palavras de Oliveira e Vianna (2010, p. 252), por uma forma de intermediação financeira. O Banco do Nordeste coloca tal estratégia administrada e regida por uma lógica neoliberal de mercado e em profunda conexão com os nexos da financeirização. Assim, observa-se uma estratégia que leva ao endividamento de pessoas empobrecidas, fragilizadas em um quadro de vulnerabilidade e dissociadas das estruturas de poder.

\footnotetext{
$4 \quad$ Ver também Zouain e Barone (2007).
} 
Por outro lado, o PAPPS busca fundamentar uma lógica associativista, cooperativa e solidária que, por meio de dimensões múltiplas, coloca o nexo econômico como um dentre os outros nexos (político, social e ambiental), além de diminuir e contrapor-se à transversalidade da competitividade capitalista por meio da criação de vínculos sociais pautados pela solidariedade. Apesar de apresentar um discurso com esse viés, a operacionalização amolda a experiência de economia solidária dentro do Banco do Nordeste e sucumbe a uma lógica de preparação de mercado do tipo tradicional para o microcrédito, como o Crediamigo.

\section{Considerações finais}

Para uma compreensão mais ampla das relações entre as interpretações apresentadas ao longo deste artigo, ou seja, dos beneficiários e dos indivíduos institucionais, gestores ou não, mostra-se fundamental entender os nexos comparativos entre essas visões em ambos os programas (Crediamigo e PAPPS) e entre os próprios programas.

Em relaçãoao Crediamigo, a comparação entretais interpretações se pauta pelaslógicas de solidariedade e de mercado: a) a primeira, para os clientes, refere-se à comoditização dos laços sociais (Schuster, 2015), que às vezes se tornam difíceis e incômodos de manter devido ao peso da dívida e da cobrança mútua entre eles, ao passo que, para os indivíduos institucionais, essa lógica se coloca como utilitária na articulação de um programa que garante o crédito; e b) na segunda, as visões se encontram no processo de bancarização, que oferece ao cliente serviços bancários e no caso dos atores institucionais, que lidam com um duplo processo, entrega-se o mercado às pessoas e as pessoas ao mercado. Em outro ponto, pauta-se pelas formulações de desenvolvimento socioeconômico, em que o beneficiário do programa observa uma ampliação da renda, mas uma estabilidade nos itens de desenvolvimento social, enquanto os indivíduos institucionais observam o crescimento financeiro do empreendimento, seu possível crescimento na escala dos programas do banco, enquanto veem o social como consequência do processo de ampliação de renda.

Em relação ao PAPPS, demonstra-se que os recursos aplicados na AMA/Budeg 'AMA não garantem a continuidade do empreendimento para que seja autossustentável ao longo do tempo. Pode-se considerar que o PAPPS causou, e continua a causar, impactos nas dimensões social, política e ambiental. Nota-se que o impulso ao empreendimento, a partir do FRS, aumentou a autoestima das associadas, fortaleceu os laços afetivos, aumentou a autonomia, o crescimento pessoal e a noção de cidadania, voltada à consciência dos direitos, fortalecendo mais a vertente política e social da AMA do que a econômica.

Assim, surge a possibilidade de uma comparação entre os dois programas, quando se verifica que os pontos das dimensões social e econômica na operacionalização do PAPPS constituem interessantes tópicos de discussão. A dimensão social tem como objetivo e 
consequência uma construção de afetividade, confiança e um sentido de solidariedade entre os membros do FRS, ou seja, a construção de um capital social, que é exigido e instrumentalizado no Programa Crediamigo. Enquanto a dimensão econômica, que no PAPPS se estabelece por conta do tipo de fundo e de retorno, é deixada em segundo plano diante das demais dimensões, no Crediamigo ela assume o protagonismo e fundamenta o programa.

Isso corrobora a interpretação dos indivíduos institucionais para pensarmos uma comparação entre os dois programas: a) no PAPPS há mudanças na construção dos laços sociais voltados à gestão do fundo e da produção e nas dimensões ambiental e política no escopo do programa, mas há deficiência na dimensão econômica quanto à geração de renda propriamente dita; e b) já no Crediamigo, há reificação do mercado, atrelada ao desenvolvimento econômico, deixando de lado os processos e as necessidades sociais dos clientes.

Dessa forma, as microfinanças no Banco do Nordeste, nos dois tipos avaliados, reificam as reconfigurações do processo neoliberal ou, mais detalhadamente, significam antes uma estratégia que aprofunda as condições socioeconômicas, o que implica a manutenção da pobreza nos estados em que atua no Nordeste brasileiro, em detrimento de um processo de autonomia e de democratização das condições.

Em suma, buscamos realizar um processo avaliativo amplo sobre dois programas complexos do Banco do Nordeste, com vistas a interpretar sentidos e significados atribuídos por todos os agentes no campo pesquisado, inseridos em sua própria cultura - seja a das comunidades alcançadas, a institucional do Banco do Nordeste ou a dos indivíduos inseridos nos programas avaliados.

Esta pesquisa avaliativa se pautou em programas de microfinanças e em seus efeitos, possibilitando, de modo geral, aprofundar o olhar sobre os limites da construção da equidade pelo esforço dos próprios indivíduos que vivenciam um quadro de exclusão social, ao passo que se almeja construir o fomento rumo ao desenvolvimento social. Ressalta-se, por fim, que os resultados da avaliação foram alcançados sob a perspectiva etnográfica, mediante pontos de vista distintos. 


\section{Referências bibliográficas}

Banco do Nordeste do Brasil. (2018). Relatório anual 2018: programas de microfinanças do Banco do Nordeste. Recuperado de http://goo.gl/OBenqD

Banco do Nordeste do Brasil. (2019). Crediamigo. Recuperado https://www.bnb.gov.br/ crediamigo

Bourdieu, P. (1986). A ilusão biográfica. In Autor, Razões práticas: sobre a teoria da razão (pp. 74-82). Campinas, SP: Papirus.

Dimenstein, G. (1997, 9 de abril). Os “inempregáveis”. Recuperado de http://goo.gl/DmWQKZ

Furtado, C. (1997). Obra autobiográfica de Celso Furtado (Tomo II). São Paulo, SP: Paz e Terra.

Furtado, C. (1998). O capitalismo global. São Paulo, SP: Paz e Terra.

Furtado, C. (2007). Formação econômica do Brasil. São Paulo, SP: Companhia das Letras.

Geertz, C. (1989). A interpretação das culturas. Rio de Janeiro, RJ: Zahar.

Gussi, A. F. (2004). Pedagogia da experiência no mundo do trabalho: narrativas biográficas no contexto de mudanças de um banco público estadual (Tese de Doutorado). Universidade Estadual de Campinas, Campinas, SP.

Gussi, A. F. (2008). Apontamentos teóricos e metodológicos para a avaliação de programas de microcrédito. AVAL: Revista Avaliação de Políticas Públicas, 1(1), 29-37.

Gussi, A. F. (2014). Avaliação de políticas públicas sob uma perspectiva antropológica. In H. A. D. Valente, R. M. N. Prados, \& C. Schmidt (Orgs.), A música como negócio: políticas públicas e direitos do autor (pp. 19-29). São Paulo, SP: Letras e Voz.

Lejano, R. P. (2011). Parâmetros para análise de políticas públicas: a fusão de texto e contexto. Campinas, SP: Arte Escrita.

Nitsch, M., \& Santos, C. A. (2001). Da repressão financeira ao microcrédito. Revista de Economia Política, 21(4), 172-183.

Oliveira, C. M. S., \& Vianna, P. J. R. (2010). Desenvolvimento regional: 50 anos do BNB. Fortaleza, CE: Banco do Nordeste do Brasil.

Raczynski, D. (1995). Estratégias para combatir la pobreza en América Latina: diagnóstico y enseñanzas de política. In Autor (Org.), Estrategias para combatir la pobreza en América Latina: programas, instituciones y recursos (pp. 11-42). Santiago, Chile: Corporación de Estudios para Latinoamérica.

Rist, G. (2002). El desarollo: historia de una creencia occidental. Madrid, España: Catarata.

Rodrigues, L. C. (2008). Proposta para uma avaliação em profundidade de políticas públicas sociais. AVAL: Revista Avaliação de Políticas Públicas, 1(1), 7-15. 
Santos, C. A. (2007). Análise de impactos socioeconômicos do microcrédito: dificuldades metodológicas e analíticas. Revista de Administração Pública, 41(1), 147-160.

Schumpeter, J. A. (1997). Teoria do desenvolvimento econômico: uma investigação sobre lucros, capital, crédito, juro e o ciclo econômico. São Paulo, SP: Nova Cultural.

Schuster, C. (2015, March 30). Your family and friends are collateral: microfinance and the social. Recuperado de https://bit.ly/30Eg9jk

Sen, A. (2010). Desenvolvimento como liberdade. São Paulo, SP: Companhia das Letras.

Zouain, D. M., \& Barone, F. M. (2007). Excertos sobre política pública de acesso ao crédito como ferramenta de combate à pobreza e inclusão social: o microcrédito na era FHC. Revista de Administração Pública, 41(2), 369-380.

\section{Para citar este artigo:}

\section{Norma A - ABNT}

GUSSI, A. F.; THÉ, R. F. S. Avaliando programas de microcrédito e economia solidária do Banco do Nordeste. Conhecer: Debate entre o Público e o Privado, v. 10, n. 24, p. 164-178, 2020.

\section{Norma B - APA}

Gussi, A. F. \& Thé, R. F. S. (2020). Avaliando programas de microcrédito e economia solidária do Banco do Nordeste. Conhecer: Debate entre o Público e o Privado, 10(24), 164-178.

\section{Norma C - Vancouver}

Gussi AF, Thé RFS. Avaliando programas de microcrédito e economia solidária do Banco do Nordeste. Conhecer: Debate entre o Público e o Privado [Internet]. 2020 [cited Out 21, 2020];10(24):164-178. Available from: https://revistas.uece.br/index.php/revistaconhecer/article/view/2071 